\title{
Uncertainty Analysis of Geothermal Well Drilling and Completion Costs
}

\author{
Maciej Z. Lukawski ${ }^{1,+}{ }^{\star}$, Rachel L. Silverman ${ }^{2,+}$, Jefferson W. Tester ${ }^{3}$ \\ ${ }^{1}$ Maciej Z. Lukawski, Cornell Energy Institute, School of Chemical and Biomolecular \\ Engineering, Cornell University, Ithaca, NY 14853,USA, mzl8@cornell.edu \\ ${ }^{2}$ Rachel L. Silverman, Sibley School of Mechanical and Aerospace Engineering, Cornell \\ University, Ithaca, NY 14853,USA, rls358@cornell.edu \\ ${ }^{3}$ Jefferson W. Tester, Cornell Energy Institute, School of Chemical and Biomolecular \\ Engineering, and Atkinson Center for a Sustainable Future, Cornell University, Ithaca, NY \\ 14853,USA, jwt54@cornell.edu
}

${ }^{+}$Equal contribution authors

* Corresponding author

Keywords:

Drilling cost, well cost, EGS, economic, drilling, uncertainty 


\section{Abstract}

The goal of this study was to characterize the uncertainty associated with the cost of drilling and completion of geothermal wells. Previous research and publications have produced correlations for the average cost of geothermal wells as a function of well depth. This project develops this concept further by using a probabilistic approach to evaluate the distribution of geothermal well costs for a range of well depths. The well cost uncertainty was characterized by identifying the main cost components of geothermal wells and quantifying the probability distributions of the key variables controlling these costs. These probability distributions were determined based on the detailed cost records of U.S. geothermal wells drilled or designed from 2009 to 2013 as well as cost data from drilling equipment manufacturers and vendors. Probability distributions of the key variables were examined to find statistically significant correlations between them. Lastly, the previously determined probability distributions of individual cost components and the correlations between them were input into WellCost Lite, a predictive geothermal drilling cost model, using the Monte Carlo method. This approach allowed us to generate the overall well cost probability distributions for 8,000-15,000 ft. (2,400-4,600 m) geothermal wells. We have shown that the median geothermal well cost increases exponentially with depth. Deep wells typically have higher cost uncertainty and more positively-skewed cost probability distributions. The correlations presented in this paper can be used to determine the economic feasibility of geothermal energy systems, assess the project risk, and facilitate investment decisions.

\section{Introduction}

U.S. electricity demand is growing due to the increasing population and ongoing electrification of end-use consumption. The total energy demand in residential and commercial sectors has also increased by $0.5 \%$ per year since 2000 despite energy conservation measures (EIA, 2015). In order to meet this growing demand while working towards carbon emissions reduction, the U.S. will need to invest in low-carbon energy technologies. While solar and wind energy will both likely play a large role in meeting the growing demand for renewable electricity, these resources are both intermittent throughout the day and seasonally and cannot provide consistent base-load power without large-scale energy storage. Geothermal energy, and specifically Enhanced Geothermal Systems (EGS), offer a potentially promising solution for the U.S. as a clean, renewable, base-load energy source (Gerber and Marechal, 2012). Despite its high potential (Tester et al., 2006), geothermal energy development in the U.S. has been relatively slow, with electric output increasing by only $2.8 \%$ per year between 2008 and 2014 (GEA, 2014). This slow growth was primarily due to low cost of natural gas, large capital investment required by geothermal projects, and the shortage of favorable policies. Another cause of slow implementation was the industry's focus on electricity generation from shallow, high-grade hydrothermal resources, which are limited in availability and found mainly in the Western U.S. (Tester et al., 2015, 2006). This narrow focus overlooks the potential for providing heat for direct-use and cogeneration applications from low- and medium-grade geothermal resources. Direct-use applications are not affected by the low heat-to-power conversion efficiencies and could be economically implemented almost anywhere in the U.S. (Beckers et al., 2014; Reber et al., 2014). 
Enhanced Geothermal Systems (EGS) are created using hydraulic stimulation to extract thermal energy from hot subsurface rocks that lack sufficient permeability and/or in situ fluid. One of the primary obstacles in developing deep EGS resources is the cost and uncertainty associated with drilling deeper wells. For low-grade EGS wells, drilling expenditures can account for more than $60-75 \%$ of total project costs (Petty et al., 2009; Tester et al., 2006). The uncertainty of well costs is also expected to increase with well depth due to more trouble time, higher formation temperatures and pressures, and increasingly complex well designs. Gaining an understanding of the drilling cost uncertainty could help geothermal developers in securing low-interest financing by reducing the infrastructure risks. Therefore, characterization of geothermal well drilling costs and uncertainty are critical to the growth and expansion of geothermal development, particularly for lower-grade, deeper resources.

Geothermal well costs have been evaluated as a function of depth by a number of authors (Augustine et al., 2006; Lukawski et al., 2014; Mansure and Blankenship, 2013; Tester et al., 2006). The study by (Augustine et al., 2006) introduced the MIT Depth Dependent (MITDD) well cost index based on tens of thousands of hydrocarbon wells drilled each year between 1976 and 2003. MITDD index was used to express the historical costs of geothermal wells in 2003 U.S. dollars. This allowed the authors to compare the costs of geothermal wells drilled at different times and create a cost vs. depth correlation in 2003 U.S. dollars. The work on MITDD index by (Augustine et al., 2006) was updated and extended by (Lukawski et al., 2014). The authors proved that the recent cost escalation rates of geothermal wells have been lower than those of oil and gas wells, and that a cost index based on hydrocarbon wells is no longer applicable to geothermal well drilling. As a result, the geothermal well cost correlation in (Lukawski et al., 2014) was based on 42 geothermal wells drilled or designed between 2008 and 2013. While both studies provide predictions for the average costs of geothermal and hydrocarbon wells at depths ranging from 3,000 to 30,000 ft. (910 to 9,100 m), they do not characterize the range of uncertainty around these average costs. Both studies point to the limited availability of geothermal drilling data as the reason for taking this deterministic approach.

The first publication to consider uncertainty as part of the EGS well costing calculation was (Yost et al., 2015). The authors used a computer program called Decision Aids for Tunneling (DAT) to model distributions of costs and times associated with each step of well drilling and completion. The overall cost of each drilling or completion activity was represented as a function of a fixed material cost, an hourly cost, and a time required for that activity. Uncertainty was factored into these equations by inputting probability distributions for all costs and times, which were obtained from the Sandia geothermal well database (Polsky et al., 2008). This yielded a method for calculating overall well cost probability distribution. However, the analysis by (Yost et al., 2015) is based on one EGS well and does not account for non-productive time (NPT). It also assumes that individual well cost components are not correlated with each other. This assumption may not always be valid; e.g. volumes of drilling mud and cement are often correlated since they are both affected by the frequency and severity of circulation loss events.

Our approach builds upon past methodologies to quantify the cost uncertainty of 8,000-15,000 ft. $(2,400-4,600 \mathrm{~m})$ deep EGS wells located in the U.S. While these depths may seem low compared to the previous well cost analyses (Augustine et al., 2006; Lukawski et al., 2014), approximately $70 \%$ of EGS wells drilled in the past fall within this range (Breede et al., 2013). Compared to the 
previous studies (Augustine et al., 2006; Lukawski et al., 2014; Mansure and Blankenship, 2008), this work presents probability distributions of well costs instead of a single, average drilling cost. Our work builds on the probabilistic approach introduced by (Yost et al., 2015) by accounting for the non-productive time, including the correlations between individual well cost components, and most importantly by analyzing a range of EGS well depths instead of a single $20,000 \mathrm{ft} .(6,100 \mathrm{~m})$ well.

Correlations presented in this paper can be used to determine the cost probability distributions for wells of any measured depth (MD) within the 8,000-15,000 ft. (2,400-4,600 m) range, assess the project risk, and facilitate investment decisions. To enhance the accuracy of our data set, we incorporated only the most recent well cost data from the U.S. geothermal industry, from the period of 2009 to 2013. Our well cost database includes fourteen hydrothermal wells drilled in the Western U.S. in similar geologic conditions, EGS wells from previous publications (Baker Hughes, 2012), and EGS wells designed in WellCost Lite for the purpose of this study. The well cost records were analyzed to: 1) determine the main variables influencing the costs of drilling and completing geothermal wells, 2) obtain the probability distribution of each of these variables, and 3) identify significant correlations between these variables. These distributions and correlations were then input to WellCost Lite, a predictive drilling cost model, using Monte Carlo method to obtain the probability distribution for the overall well cost as a function of depth.

The geothermal wells analyzed in this work were drilled in or designed for locations in the United States. Consequently, our analysis uses U.S. drilling, labor, and material costs. As a result of the limited access to detailed drilling cost data for recently completed geothermal wells, our database contains wells drilled in various locations. This introduces an additional scatter to the well cost database due to the differences in formation lithology and various location-specific costs such as rig rates. However, while the cost differences between individual geothermal fields are important, accounting for them reduces the overall cost variability by only $11 \%$ (Mansure et al., 2006). With a more extensive well cost database, presented methodology could also be used to produce more accurate correlations for individual geologic provinces.

\section{Methodology}

The overview of used methodology is presented as a flowchart in Figure 1. First, detailed well data for this study were gathered from several sources, including ten EGS wells modeled in WellCost Lite - a predictive drilling cost software developed by Bill Livesay and co-workers at Sandia National Lab (Tester et al., 2006). The well expenditures were evaluated using 2012 costs for individual well services and consumables. Other well cost data sources included fourteen actual hydrothermal wells drilled in the Western U.S. in similar geologic settings from 2008 to 2013 and eight EGS wells whose costs were estimated by drilling engineers (Baker Hughes, 2012). Table A-1 in the appendix provides a list of these wells with summary statistics that include drilling cost, depth, year drilled, and total drilling days. 


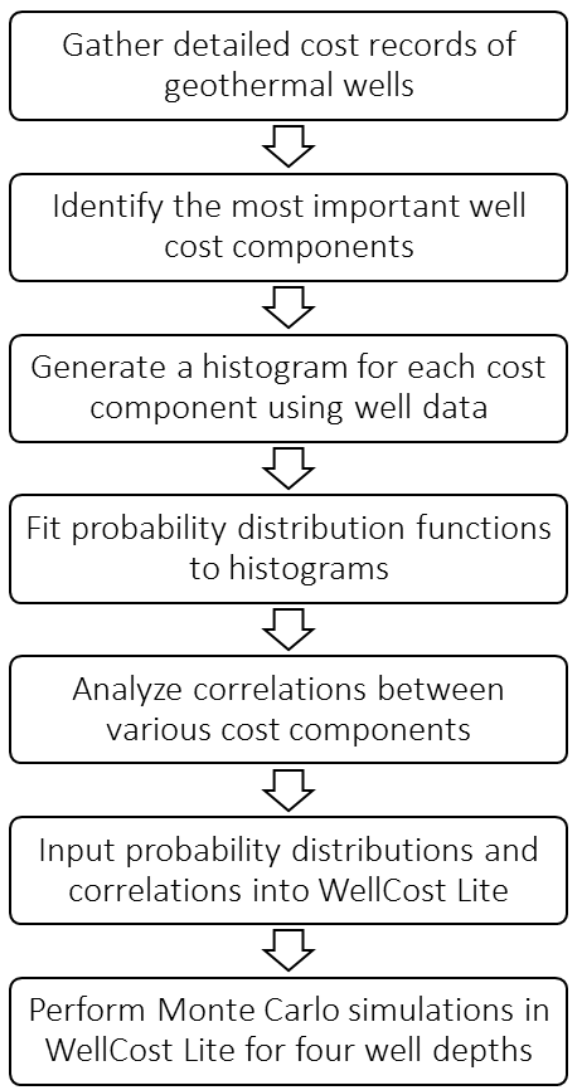

Figure 1: Flowchart representing the used methodology

Itemized costs for each well were grouped according to 24 categories commonly used in authorizations for expenditure (AFE) - the term for drilling cost worksheets used in the industry. These 24 cost categories were then sorted by their contribution to the total well cost. A representative itemized well cost breakdown from an 8,000 ft. $(2,400 \mathrm{~m})$ EGS well is shown in Figure 2. Within each of these cost categories, data were organized by the well interval. Then individual cost components comprising each cost category were divided by interval depth or required time, yielding specific costs in $\$ / \mathrm{ft}$. or $\$ /$ day. These specific costs were then sorted into bins and plotted in histograms to reveal the shape of their probability distributions. Figure 3 shows an example of such a histogram for depth-normalized drill bit cost. Using these histograms, supplemented by advice from geothermal drilling engineers, each cost component was approximated by a common distribution functional form, such as normal, triangular, or Weibull. For example, the depth-normalized drill bit cost was approximated by a normal probability distribution, shown by the fitted curve in Figure 3. The type of probability distribution fitted to each cost category and the parameters of each distribution are given in Table A-2 in the appendix. This table includes the distributions for the fourteen most important categories, each of which is responsible for $2.5 \%$ or more of total well cost, as shown in Figure 2. In reality, the WellCost Lite model contains a much more detailed and complex cost breakdown, with many of these fourteen basic categories containing several sub-categories. A total of 45 sub-categories were modeled with fitted distributions in WellCost Lite. In addition, some costs were not characterized probabilistically due to insufficient detail of the data sets, or because of their very low contribution to the total well cost. These items are treated as constants and are labeled "deterministic" in Table A-2. 


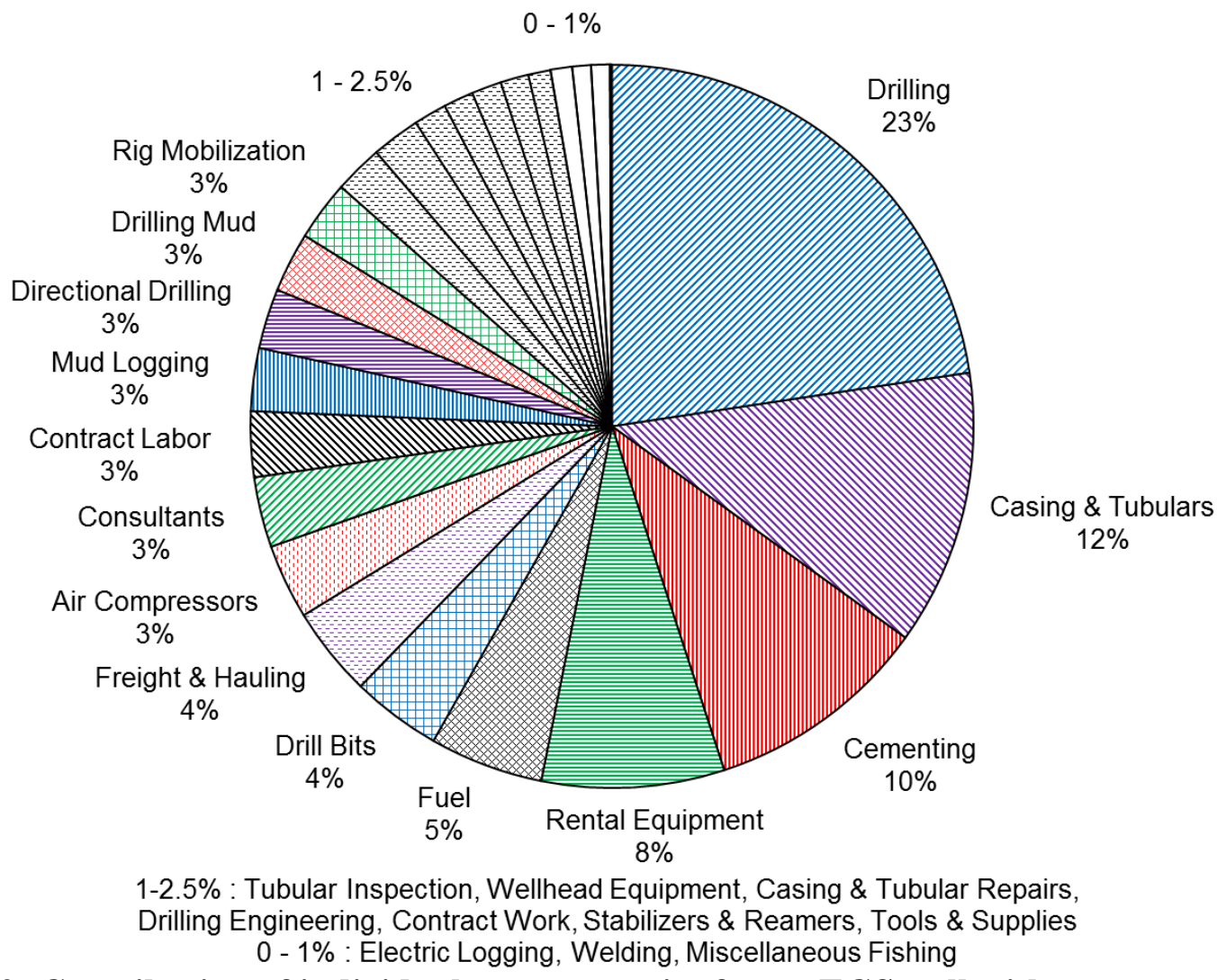

Figure 2: Contribution of individual cost categories for an EGS well with a measured depth (MD) of $8,000 \mathrm{ft}$. $(2,400 \mathrm{~m})$

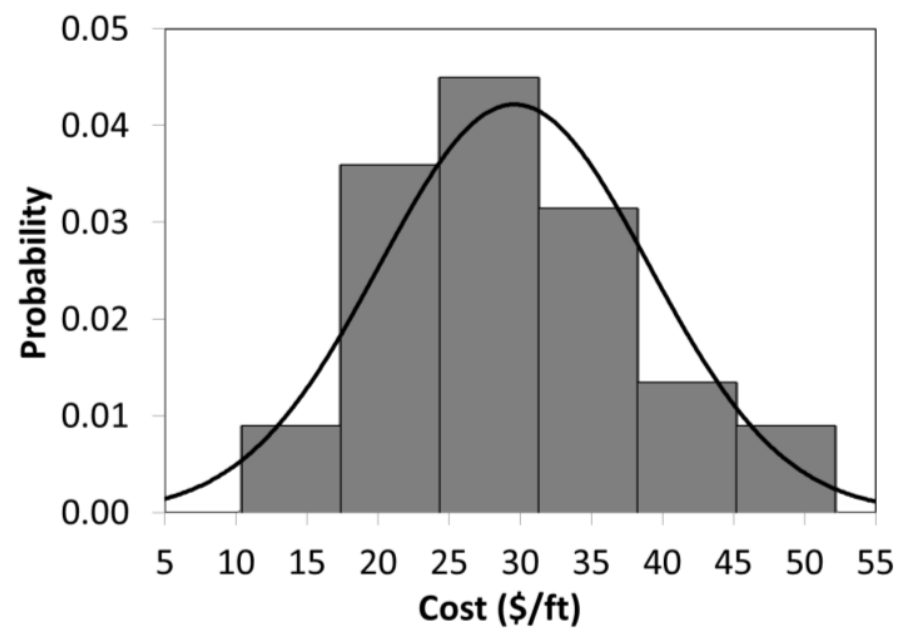

Figure 3: Example probability distribution of individual well cost component: normalized drill bit cost (\$ per ft. of MD)

As a next step, the categories with the highest contributions to the total well cost were searched for evidence of correlations between variables. We analyzed the Pearson correlation coefficients (r) between various parameters affecting the overall well cost including: rate of penetration (ROP), interval depth, number of drill bits used, and the costs of mud, cement, and directional 
drilling. We calculated both the correlation coefficients between individual parameters for various well intervals (e.g. ROPs in intervals 2 vs. 3) and between various cost components for the same well interval (e.g. mud cost vs. cement cost in interval 3). Including such correlations is a crucial step in quantifying the uncertainty because a mishap or holdup encountered during drilling is rarely a random, isolated event. Rather, it is a symptom of a larger issue such as unfavorable geological conditions or less experienced drilling crew. Such problems may affect many aspects of drilling and will likely drive up costs across several categories. For example, extraordinarily high drilling mud costs are often a symptom of significant loss of circulation, which is caused by a highly permeable formation section. Under such conditions, it is likely that cement costs would be similarly affected, as cement would also be lost to the formation. Therefore, one would expect to see a positive correlation between drilling mud and cement costs, and failing to account for this correlation would lead to an underestimation of uncertainty in the total well cost. Analysis of the most influential cost categories yields seven statisticallysignificant ( $\mathrm{p}$-value<0.1) linear correlations listed in Table 1.

Table 1: Statistically-significant correlations between individual well cost components are quantified using Pearson correlation coefficient ( $r)$, coefficient of determination $\left(r^{2}\right)$, and pvalue.

\begin{tabular}{|l|l|l|l|r|}
\hline Variable Y & Variable X & \multicolumn{1}{c|}{$\mathbf{r}$} & $\mathbf{r}^{\mathbf{2}}$ & \multicolumn{1}{c|}{ p-value } \\
\hline Mud (Interval 3) & Cement (Interval 3) & 0.86 & 0.75 & 0.0001 \\
\hline Mud (Interval 4) & Cement (Interval 4) & 0.78 & 0.61 & 0.0015 \\
\hline Cement (Interval 1) & Depth (Interval 1) & 0.70 & 0.50 & 0.0072 \\
\hline Mud (Interval 1) & Cement (Interval 1) & 0.65 & 0.42 & 0.0162 \\
\hline Mud (interval 2) & Cement (Interval 2) & 0.56 & 0.31 & 0.0472 \\
\hline Cement (Interval 2) & ROP (Interval 2) & -0.52 & 0.27 & 0.0711 \\
\hline ROP (Interval 2) & Depth (Interval 2) & -0.49 & 0.24 & 0.0885 \\
\hline
\end{tabular}

Several of the correlations in this table are between mud and cement, confirming that they may be treated as paired variables following the logic presented above. A correlation is also observed between cement cost and depth of the first interval, as the volume of cement would be affected by the interval length. The negative correlations between the rate of penetration (ROP) and depth, as well as between cement and ROP, both agree with our expectations. At greater depths, the driller is more likely to encounter lower penetration rates and trouble, whether because of geology or equipment failures, causing the ROP to decrease. In the cases where ROP decreases due to circulation problems, the cement cost will increase, as cement may be lost to the formation in the same well interval.

Many of the correlations presented in Table 1 have low coefficient of determination $\left(\mathrm{r}^{2}\right)$ values, indicating that there is a substantial scatter and that just a fraction of variability in cost component $\mathrm{Y}$ can be explained by the values of cost component $\mathrm{X}$. While we acknowledge that the variables in Table 1 are not as well correlated as many engineering variables, the drilling process is stochastic and inherently harder to predict than many physical phenomena. 
Upon characterizing the probability distributions of individual cost factors and finding the most significant correlations between them, these functions were implemented in the WellCost Lite model using Monte Carlo simulator @RISK (Palisade Corporation, 2015). @RISK software allows the user to input probability distributions into cells in a WellCost Lite spreadsheet and to perform a Monte Carlo simulation yielding total well cost distribution. The WellCost Lite worksheets were completed for four well designs with depths of 8,000 ft. $(2,400 \mathrm{~m}), 10,000 \mathrm{ft}$. $(3,000 \mathrm{~m}), 12,000 \mathrm{ft} .(3,700 \mathrm{~m})$, and 15,000 ft. $(4,600 \mathrm{~m})$. Each of these wells has 3 casing strings (surface, intermediate, and production) in addition to conductor casing. The last well section is drilled open hole with an 8-1/2" diameter. Deep wells with abnormal pore pressures or significant lost circulation could require another drilling casing or liner, resulting in more complex and expensive designs. For each of the 4 well models in WellCost Lite, 45 probability distributions, the most significant of which are listed in Table A-2, were input along with the correlations listed in Table 1. In order to prevent the simulation from producing unrealistically high results, all continuous distributions were truncated with a lower boundary at P1 (first percentile) and an upper boundary at P99 (ninety-ninth percentile). Monte Carlo simulations with 100,000 iterations were run for each of the 4 well depths, yielding the overall well cost distributions.

\section{Results}

The cumulative probability curves for the overall cost of 8,000-15,000 ft. $(2,400-4,600 \mathrm{~m})$ wells are presented in Figure 4. The results of the Monte Carlo simulations performed on the four WellCost Lite models were approximated using fitted probability distribution curves. Several functional forms (normal, log-normal, gamma, logistic, Weibull, gamma, triangular) were examined and gamma distribution was determined to be the best fit for all of the simulation results. Figure 4 shows the comparison of the cumulative well cost probabilities obtained from the Monte Carlo simulations (in red) with the fitted gamma distributions (in black). The coefficients of determination for the fitted gamma functions were at least 0.998 . 


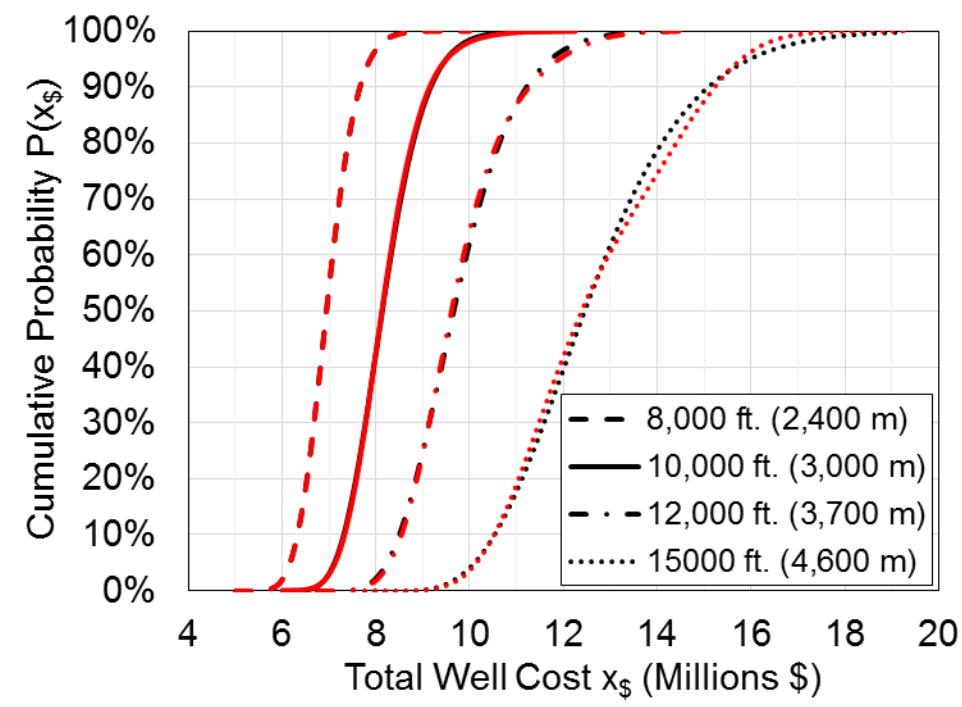

Figure 4: Cumulative probability distribution $P(x \$)$ of the total cost of 8,000-15,000 ft. $(2,400-4,600 \mathrm{~m})$ geothermal wells. Results of the Monte Carlo simulations in WellCost Lite (in red) are approximated with gamma functions (in black).

The gamma functions expressing the cumulative well cost probability in Figure 4 are presented as probability density functions in Figure 5. The curves in Figure 5 may be viewed as histograms, where each curve corresponds to a specific well depth and the area under each curve equals 1 .

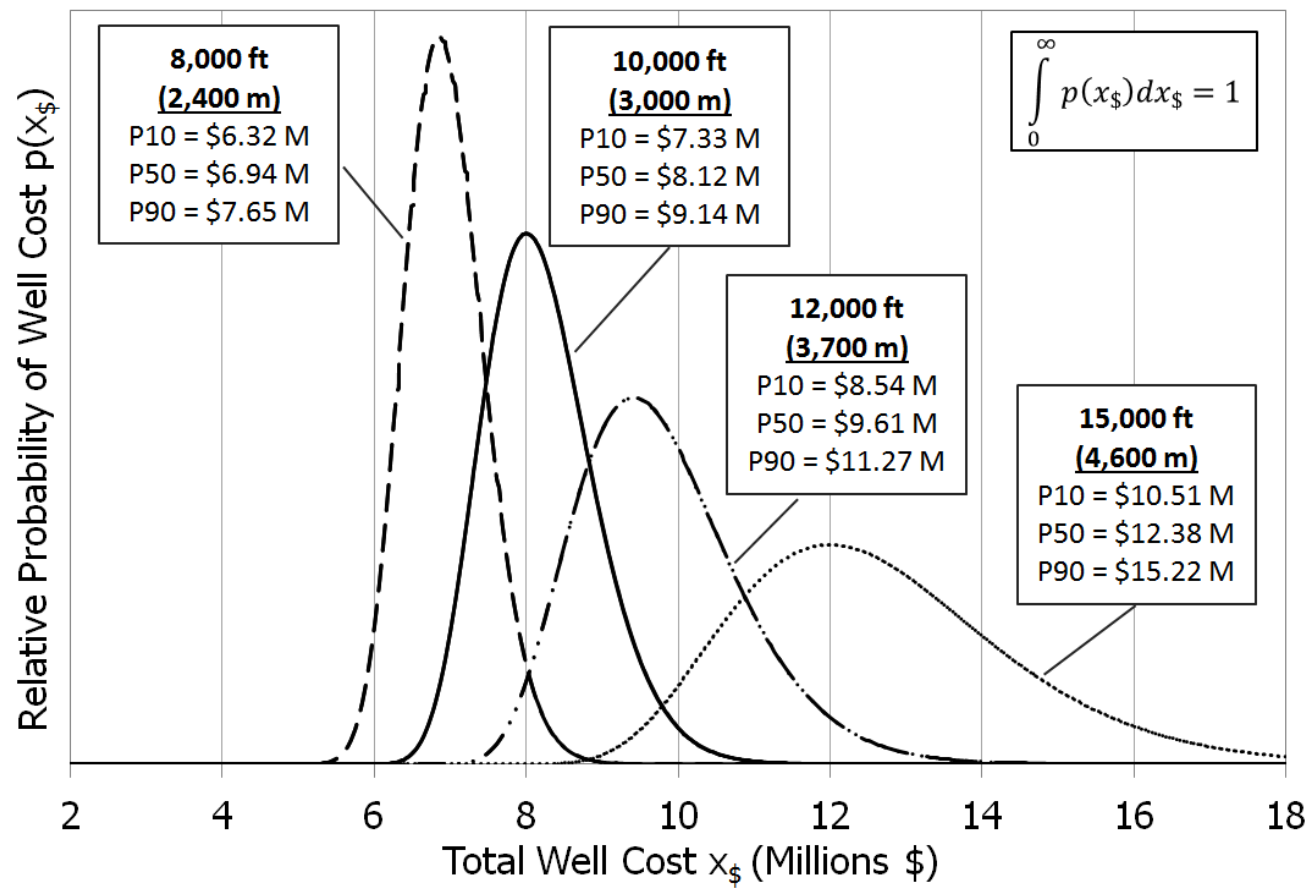

Figure 5: The probability of occurrence of a specific well cost $p(x \$)$ versus well cost is presented for wells with 4 different measured depths (MD). 
As expected, the curves shift to the right (higher well cost) with increasing well depth. The probability distributions for deep wells are wider and less peaked, indicating increased well cost uncertainty. While for a 8,000 ft. $(2,400 \mathrm{~m})$ well, tenth percentile (P10) and ninetieth percentile (P90) correspond to $91 \%$ and $110 \%$ of the median (P50) cost, for a $15,000 \mathrm{ft}$. (3,000 m) well they represent $85 \%$ and $123 \%$ of $\mathrm{P} 50$, respectively. All four distributions have a positive skew, i.e. the tail on the right side of the mean is longer than that on the left, and the skewness increases with the well depth. This is due to a higher likelihood of trouble in deeper wells. It also indicates that deeper wells are more likely to become 'black swans' - rare, expensive, and hard-to-predict wells.

The gamma probability distributions presented in Figure 5 take the form:

$$
p\left(x_{\$}\right)=\frac{\beta^{\alpha}}{\Gamma(\alpha)}\left(x_{\$}-x_{0}\right)^{\alpha-1} e^{-\beta\left(x_{\$}-x_{0}\right)}
$$

Where $\alpha$ is the shape parameter, $\beta$ is the rate parameter, $x_{\$}$ is the well cost in U.S. dollars, $x_{0}$ is the shift (i.e. the y-intercept of the fitted distribution) in U.S. dollars, and $\Gamma$ is the gamma function defined as:

$$
\Gamma(\alpha)=\int_{0}^{\infty} z^{\alpha-1} e^{-z} d z
$$

The input parameters for the gamma probability distributions are given in Table 2

Table 2: Parameters for gamma distributions describing total well costs

\begin{tabular}{|r|r|r|l|}
\hline Depth (ft.) & \multicolumn{1}{|c|}{$\boldsymbol{\alpha}$} & \multicolumn{1}{c|}{$\boldsymbol{\beta}$} & xo (shift) \\
\hline 8,000 & 34.295 & 89,420 & $3,900,000$ \\
\hline 10,000 & 14.188 & 193,900 & $5,450,000$ \\
\hline 12,000 & 8.830 & 363,100 & $6,570,000$ \\
\hline 15,000 & 7.620 & 658,400 & $7,640,000$ \\
\hline
\end{tabular}

For practical purposes, it is useful to provide equations for well cost distributions at all depths within the 8,000-15,000 ft. $(2,400-4,600 \mathrm{~m})$ range, to allow drilling engineers and investors to easily estimate the magnitude of cost uncertainty for any given well depth. The following equation was obtained by interpolation of results for four geothermal wells presented in Figure 5 and Table 2. The equation can be used to evaluate $\alpha, \beta$, and shift parameters for wells with measured depths from $8,000 \mathrm{ft}$. to $15,000 \mathrm{ft}$. $(2,400$ to $4,600 \mathrm{~m})$ :

$$
\mathrm{y}=\mathrm{Ad}^{3}+\mathrm{Bd}^{2}+\mathrm{Cd}+\mathrm{D}
$$

Where y represents the parameter in question (either $\alpha, \beta$, or shift) and $\mathrm{d}$ represents measured well depth (MD) in meters. The values of constants A through D are listed in Error! Reference source not found. When using data from Table 2 and Error! Reference source not found. it is essential to use all significant figures, and not to extrapolate the results outside of the 8,000$15,000 \mathrm{ft}$. $(2,400-4,600 \mathrm{~m})$ depth range. All parameters of the gamma distribution can then be predicted with an error of less than $0.5 \%$. 
Table 3: Constants used as an input to Eqn. 3 for evaluating $\alpha, \beta$, and shift parameters as functions of measured well depth (MD)

\begin{tabular}{|l|r|r|r|r|}
\hline $\mathbf{y}$ & \multicolumn{1}{|l|}{ A } & \multicolumn{1}{l|}{ B } & C & \multicolumn{1}{l|}{ D } \\
\hline $\boldsymbol{\alpha}$ & $-6.986 \mathrm{E}-09$ & $8.3695 \mathrm{E}-05$ & $-3.3377 \mathrm{E}-01$ & $4.518 \mathrm{E}+02$ \\
\hline $\boldsymbol{\beta}$ & $-2.676 \mathrm{E}-05$ & $3.3170 \mathrm{E}-01$ & $-1.0420 \mathrm{E}+03$ & $1.046 \mathrm{E}+06$ \\
\hline Shift & 0 & $-4.870 \mathrm{E}-01$ & $5.164 \mathrm{E}+03$ & $-5.783 \mathrm{E}+06$ \\
\hline
\end{tabular}

In order to compare the results of this work with previous publications, the predicted minimum well cost (Pmin), tenth percentile (P10), median (P50), ninetieth percentile (P90), and the maximum (Pmax) were plotted as functions of well depth in Figure 6 and Figure 7. Also displayed are average geothermal and oil and gas well costs from (Lukawski et al., 2014). Previously published results (Lukawski et al., 2014) are based on a larger number of wells (42 geothermal and 25,000 oil and gas) but they lack detailed cost information required for a probabilistic cost study.

Although the 8,000-15,000 ft. (2,400-4,600 m) well depth range investigated in this study may seem low compared to the depths considered in previous publications, approximately $70 \%$ of the existing EGS wells fall into this depth range (Breede et al., 2013). Probabilistic analysis of shallower and deeper wells is currently limited by the availability of detailed drilling records, but may become possible as more geothermal wells are drilled or their cost data are shared within the industry.

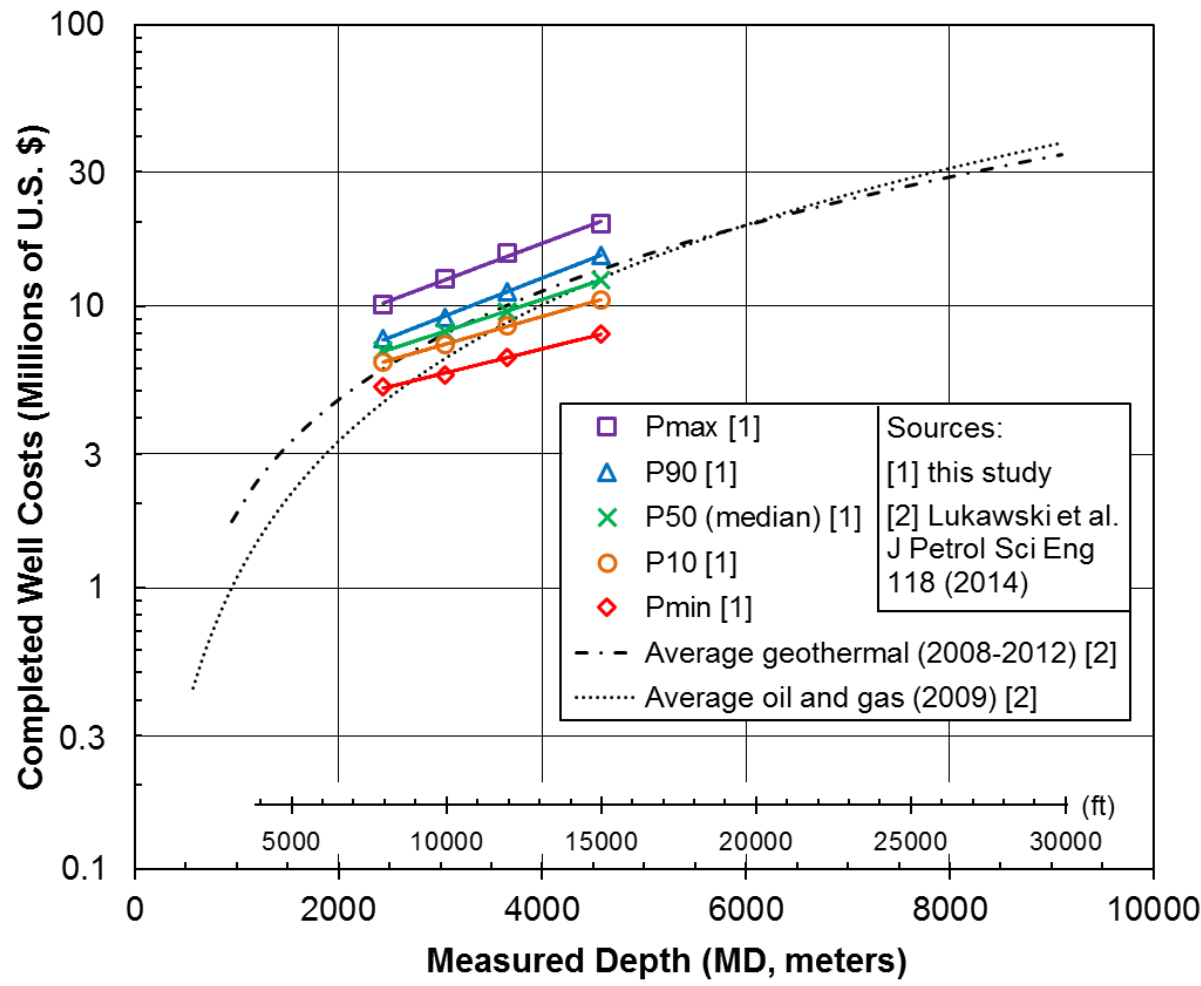

Figure 6: Semi-log graph of geothermal well cost curves from this work compared to average geothermal and hydrocarbon well costs from (Lukawski et al., 2014) 


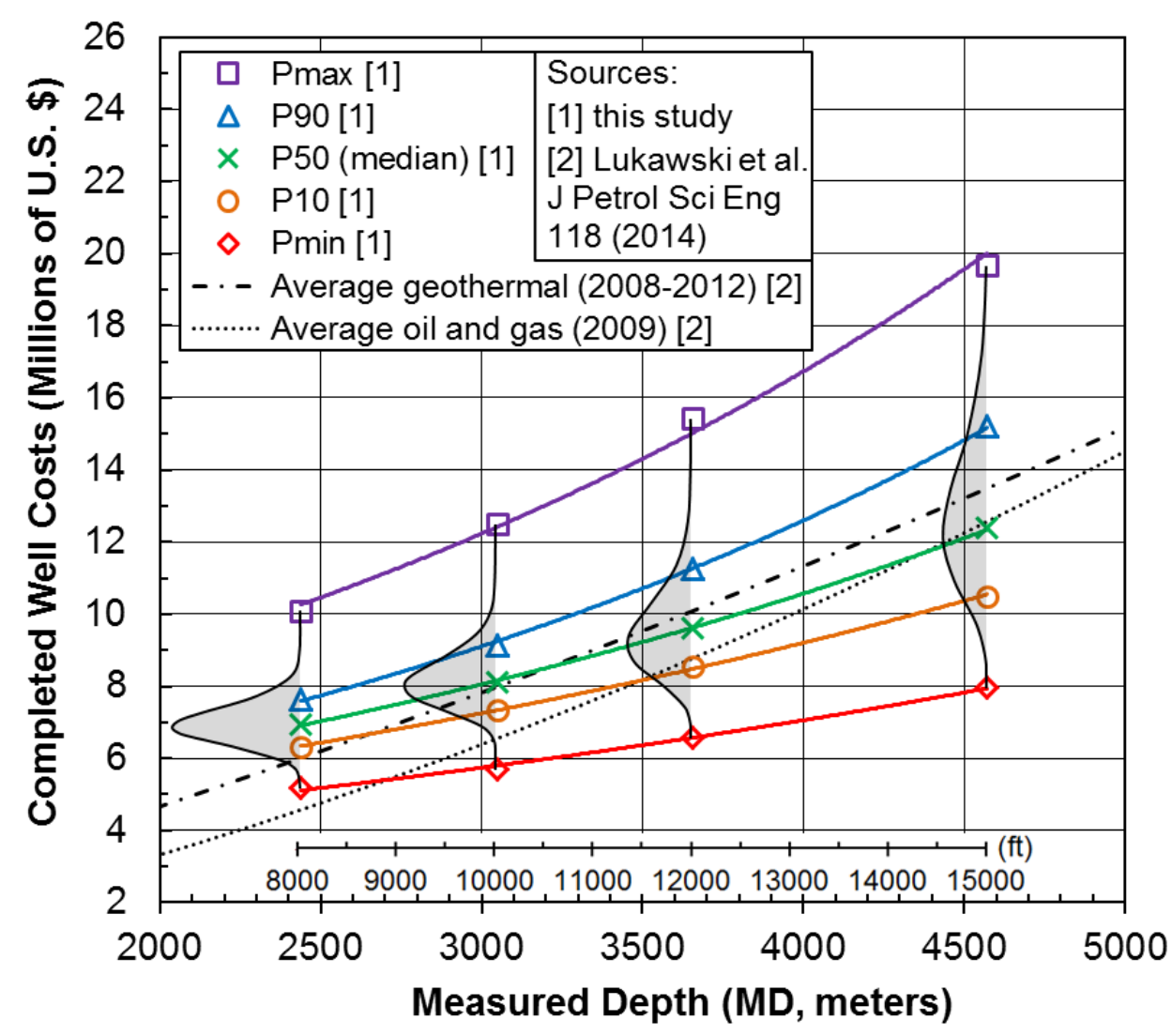

Figure 7: Results from Figure 6 plotted on a linear graph. The grey shaded areas denote cost probability distributions for four geothermal wells as described by Eqn. 1.

As shown in the previous analyses (Augustine et al., 2006; Lukawski et al., 2014; Mansure and Blankenship, 2013), the increase in cost of geothermal wells with depth is stronger than linear. In this study, the median well costs, Pmin, P10, P90, and Pmax are approximated as exponential functions of depth and presented as colored lines in Figure 6 and Figure 7:

$$
\Phi=a \cdot \exp (b \cdot d)
$$

where $\Phi$ is the completed well cost in U.S. dollars (2012), $d$ is the measured depth (length of the borehole along its path) in meters, and the values of constants a and b are given in Table 4. All five exponential fits have coefficients of determination of at least 0.995 .

Table 4: Constants used as an input to Eqn. 4 to produce correlations for well cost curves presented in Figure 6 and Figure 7.

\begin{tabular}{|l|l|l|}
\hline $\boldsymbol{\Phi}$ & a & b \\
\hline Pmin & 3.09 & $2.06^{*} 10^{-4}$ \\
\hline P10 & 3.54 & $2.39 * 10^{-4}$ \\
\hline P50 (median) & 3.56 & $2.72 * 10^{-4}$ \\
\hline P90 & 3.44 & $3.25^{*} 10^{-4}$ \\
\hline Pmax & 4.78 & $3.13 * 10^{-4}$ \\
\hline
\end{tabular}


The average geothermal well cost curve from the previous study (Lukawski et al., 2014) falls within the uncertainty range of our simulation results as shown in Figure 6 and Figure 7. For $8,000 \mathrm{ft}$. $(2,400 \mathrm{~m})$ and 15,000 ft. $(4,600 \mathrm{~m})$ wells, this curve indicates costs that are $13 \%$ below and $9 \%$ above our median well cost (P50), respectively. This difference may be attributed to the specific design of the four geothermal wells used in this study, and to the advancements in drilling technology. While all four wells modeled in this study have 3 casing intervals, some actual geothermal wells may require an additional casing string or liner. The deeper the well is, the more likely it is to need an additional casing interval. An added intermediate liner would increase the median cost of $12,000 \mathrm{ft}$. $(3,700 \mathrm{~m})$ and $15,000 \mathrm{ft}$. $(4,600 \mathrm{~m})$ wells by approximately $15 \%$, thus reducing the mismatch between the results of this and the previous study (Lukawski et al., 2014). The low slope of the median (P50) cost curve also reflects the recent decrease in drilling cost at greater depths. According to previous analyses, drilling deep wells has become more affordable largely due to the advancements in drilling technology including hightemperature electronics, improved roller cone bits, and availability of large, >1500 hp drilling rigs (Lukawski et al., 2014; Tester et al., 2006).

While most recent geothermal well costs fall within the range estimated in this study, individual wells may be cheaper than Pmin or more expensive than Pmax. Well cost may fall below the minimum curve for two reasons, neither of which can be easily predicted in a general model such as WellCost Lite. First, as a result of poor management practices, developers may use excess materials, such as casing, left over from a previous well without reporting their costs in the AFE. The second potential source is learning: as a developer drills many wells within the same geothermal field, a model of the sub-surface geology is developed so that future wells can be strategically placed to avoid undesirable features, and the selection of well design, drilling methods, and operations can be optimized to reduce risks and improve performance for the specific geology. As the developer learns and understands the nature of the field, consecutive wells can typically be drilled and completed faster and with less non-productive time (NPT). Significant learning effects have been observed and quantified in both geothermal (Prihutomo and Arianto, 2010; Sanyal and Morrow, 2012) and oil and gas fields (Brett and Millheim, 1986; Ikoku, 1978). Well costs may also exceed the Pmax values presented in Figure 6 andFigure 7 since it is impossible to predict the absolutely worst case scenario corresponding to Pmax (McIntosh, 2010).

The slope of the average oil and gas cost curve presented in Figure 6 and Figure 7 is much steeper than the slopes of geothermal cost curves. The costs of oil and gas wells increase more rapidly with depth, as they typically require complex casing programs to tap deep, overpressured hydrocarbon reservoirs. Deep geothermal formations are often underpressured and thus need less complex well designs. In contrast, shallow geothermal wells are often more expensive due to more complex casing designs, higher wellbore diameters, more complex lithologies including harder and fractured rocks, and higher rig mobilization costs. Whereas oil and gas drilling usually occurs in high-density drill patterns, geothermal drilling quite often occurs in sparse patterns where few wells are drilled. The lower number of geothermal wells drilled within individual fields reduces the potential cost savings due to learning effects. In addition, most drill crews have more experience in oil and gas settings compared to geothermal, which affects the drilling efficiency and cost. 
Finally, the results of the Monte Carlo simulations allowed us to determine which cost factors hold the most influence over the well cost uncertainty. Figure 8 shows the tornado diagram of the most influential drilling cost parameters for an 8,000 ft. $(2,400 \mathrm{~m})$ geothermal well in order of decreasing uncertainty. Some of these parameters are listed individually for each drilling interval. Each bar represents the deviation from the mean well cost brought about by a swing through the full range of possible values for the corresponding variable. According to this diagram, the most important factors in determining uncertainty are the rate of penetration (ROP), cost of cement and drilling bits, rig day rate, and drilling mud cost. This list remains consistent for deeper wells, with the exception that drilling mud becomes less important, while directional drilling and trouble both move significantly higher on the list. These changes are reasonable because both directional drilling and trouble costs increase with depth, and they also become less predictable due to a wide range of geological conditions encountered at greater depths.

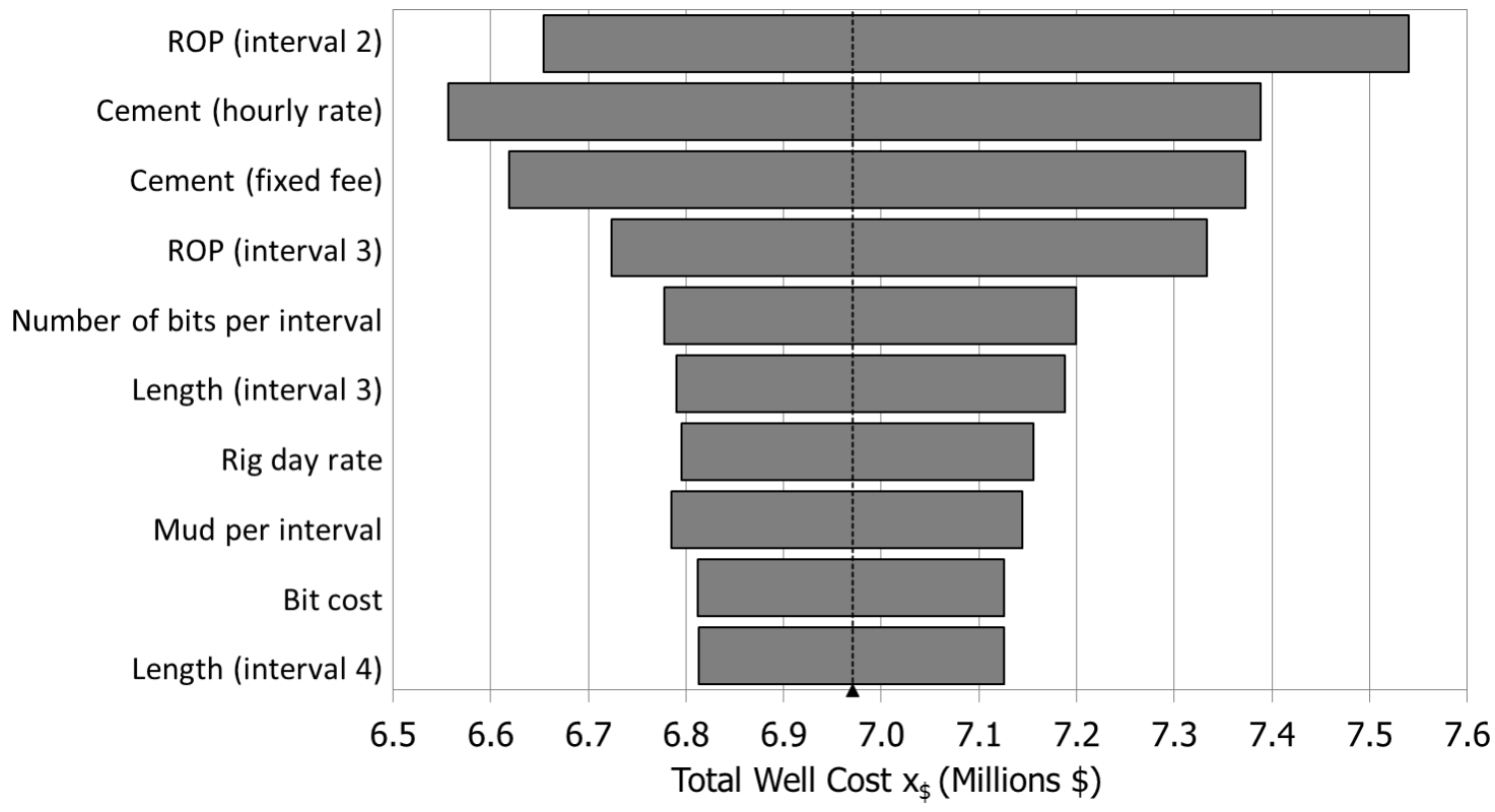

Figure 8: Leading factors contributing to cost uncertainty of an 8,000 ft. $(2,400 \mathrm{~m})$ geothermal well. The inputs were ranked by their effect on the output mean.

\section{Conclusions}

The application of Monte Carlo method to the predictive drilling cost model WellCost Lite allowed us to characterize the cost uncertainty of $8,000 \mathrm{ft}$. $(2,400 \mathrm{~m})$ to $15,000 \mathrm{ft}$. $(4,600 \mathrm{~m})$ EGS wells. The results are presented in the form of equations which can be used by drilling engineers, researchers, and investors to estimate the probability distribution of geothermal well costs. The median well costs obtained with our probabilistic approach match closely the average well costs from a previous study based on a larger number of geothermal wells (Lukawski et al., 2014).

Quantitatively, our results display three trends, which are characteristic of drilling activities:

1. Well costs increase exponentially with depth as a result of the more difficult drilling environment. 
2. Uncertainty of well cost increases with depth due to increased likelihood of trouble and less predictable drilling conditions.

3. Deep wells have more positively-skewed cost probability distributions. As a result of increased trouble time, probability distributions for deep wells have long, narrow tails stretching far into the high cost region.

The last two characteristics have been quantified in literature for oil and gas wells, but never before for geothermal boreholes.

The main limitations of this work and other analyses in this field result from the limited access to geothermal well cost data. Although it is believed that more than 4,000 geothermal wells have been drilled historically worldwide (Sanyal and Morrow, 2012), costs on less than 5\% of them have been published. Detailed well costs required for probabilistic studies are even scarcer. In addition to refining our estimates, a larger well cost database could allow us to extend this analysis beyond the $8,000-15,000 \mathrm{ft}$. (2,400-4,600 m) depth range. Moreover, it is likely that many well cost components treated as uncorrelated in this study would actually become correlated if a larger data set were available. Including such additional correlations would increase the well cost uncertainty. Having a larger geothermal well database would also improve our insight into the costs of trouble events and, in particular, rare and expensive 'worst case' scenarios. In addition, we make no distinction between drilling costs in different geologic provinces. This is an obvious simplification, as drilling times and costs highly depend on subsurface characteristics, which vary geographically.

At a time when much of the world is searching for reliable renewable energy sources and geothermal is often marginalized due to high and uncertain capital investment costs, evaluation of drilling cost uncertainty could greatly contribute to the advancement of geothermal energy as a base-load, sustainable source of heat and electricity.

\section{Acknowledgements}

The authors are very grateful to the Cornell Energy Institute, the Atkinson Center for Sustainable Future, as well as the NSF Earth-Energy IGERT program for partial financial support of this work. We also appreciate the support from the U.S. Department of Energy provided in the form of research grants \#DE-EE0002745 and \#DE-EE0002852. We would also like to express our gratitude to Louis Capuano Jr. and Louis Capuano III, the late Bill Livesay, Bill Eustes, Paul Graham, Karl Urbank, Joe Wangsness, Abraham Stroock, Lawrence Cathles, Chad Augustine, Brian Anderson, and Michal Moore, who provided advice on this work.

\section{Bibiliography}

Augustine, C., Tester, J., Anderson, B., 2006. A Comparison of Geothermal with Oil and Gas Well Drilling Costs, in: Proceedings, Thirty-First Workshop on Geothermal Reservoir Engineering, Stanford University. Stanford, CA, USA, p. 15.

Baker Hughes, 2012. Enhanced Geothermal Systems Directional Well Costing. Sandia National Laboratories, PO No: 1290712. 
Beckers, K.F., Lukawski, M., Anderson, B., Moore, M., Tester, J., 2014. Levelized costs of electricity and direct-use heat from Enhanced Geothermal Systems. J. Renew. Sustain. Energy 6. doi:10.1063/1.4865575

Breede, K., Dzebisashvili, K., Liu, X., Falcone, G., 2013. A systematic review of enhanced (or engineered) geothermal systems: past, present and future. Geotherm. Energy 1. doi:10.1186/2195-9706-1-4

Brett, J., Millheim, K., 1986. The Drilling Performance Curve: A Yardstick for Judging Drilling Performance. SPE 1536212.

EIA, 2015. Total energy statistics [WWW Document]. URL http://www.eia.gov/totalenergy/data/annual/index.cfm (accessed 9.13.15).

GEA, 2014. 2014 Annual U.S. \& Global Geothermal Power Production Report.

Gerber, L., Marechal, F., 2012. Design of Geothermal Energy Conversion SystemsWith a Life Cycle Perspective. Proc. Thirty-Seventh Work. Geotherm. Reserv. Eng. Stanford Univ.

Ikoku, C.U., 1978. Application of Learning Curve Models to Oil and Gas Well Drilling. SPE 711912.

Lukawski, M.Z., Anderson, B.J., Augustine, C., Capuano, L.E., Beckers, K.F., Livesay, B., Tester, J.W., 2014. Cost analysis of oil, gas, and geothermal well drilling. J. Pet. Sci. Eng. 118, 1-14. doi:10.1016/j.petrol.2014.03.012

Mansure, A.J., Bauer, S.J., Livesay, B.J., Petty, S., 2006. Geothermal Well Cost Analyses 2006. Geotherm. Resour. Counc. Trans. 30, 271-276.

Mansure, A.J., Blankenship, D.A., 2008. Geothermal Well Cost Analyses 2008. Geotherm. Resour. Counc. Trans. 32, 43-48.

Mansure, A.J., Blankenship, D.A., 2013. Geothermal Well Cost Update 2013. GRC Trans. 37, 629-632.

McIntosh, J., 2010. The Future Ain't What It Used to Be , Or Is It? J. Pet. Technol. 62, 48-50.

Palisade Corporation, 2015. @ Risk software.

Petty, S., Bour, D., Livesay, B., Baria, R., Adair, R., 2009. Synergies and Opportunities Between EGS Development and Oilfield Drilling Operations and Producers. SPE 121165.

Polsky, Y., Capuano, L.J., Finger, J., Huh, M., Knudsen, S., Mansure A J, Raymond, D., Swanson, R., 2008. Enhanced Geothermal Systems (EGS) Well Construction Technology Evaluation Report. Sandia Rep. SAND2008-7866 108.

Prihutomo, M.J., Arianto, S., 2010. Drilling Performance Improvements of Salak Geothermal Field, Indonesia 2006 - 2008, in: Proceedings World Geothermal Congress 2010. Bali, Indonesia, p. 10.

Reber, T.J., Beckers, K.F., Tester, J.W., 2014. The transformative potential of geothermal heating in the U.S. energy market: A regional study of New York and Pennsylvania. Energy Policy 70, 30-44. doi:10.1016/j.enpol.2014.03.004

Sanyal, S.K., Morrow, J.W., 2012. Success and the Learning Curve Effect in Geothermal Well Drilling - a Worldwide Survey, in: Proceedings Thirty-Seventh Workshop on Geothermal Reservoir Engineering, Stanford University. Stanford, CA, USA, p. 8.

Tester, J., Reber, T., Beckers, K., Lukawski, M., Camp, E., Aguirre, G.A., Jordan, T., Horowitz, F., 2015. Integrating Geothermal Energy Use into Re-building American Infrastructure. Proc. World Geotherm. Congr. 2015. 
Tester, J.W., Anderson, B.J., Batchelor, A.S., Blackwell, D.D., DiPippo, R., Drake, E.M., Garnish, J., Livesay, B., Moore, M.C., Nichols, K., Petty, S., Toksoz, M.N., Veatch, Ralph W, J., 2006. The Future of Geothermal Energy: Impact of Enhanced Geothermal Systems (EGS) on the United States in the 21st Century. MIT.

Yost, K., Valentin, A., Einstein, H.H., 2015. Estimating cost and time of wellbore drilling for Engineered Geothermal Systems (EGS) - Considering uncertainties. Geothermics 53, 8599. doi:10.1016/j.geothermics.2014.04.005

\section{Appendix}

Table A-1 Summary statistics of geothermal well data set. All wells were drilled at or designed for the U.S. locations. Baker Hughes wells were obtained from (Baker Hughes, 2012)

\begin{tabular}{|l|l|r|r|r|r|r|}
\hline \multicolumn{1}{|c|}{ Well name } & Well type & $\begin{array}{c}\text { Total cost } \\
(\mathbf{\$ M})\end{array}$ & $\begin{array}{c}\text { Total MD* } \\
(\mathbf{f t} .)\end{array}$ & $\begin{array}{c}\text { Total MD* } \\
(\mathbf{m})\end{array}$ & Year & $\begin{array}{c}\text { Total } \\
\text { days }\end{array}$ \\
\hline Hydrothermal 1 & Production & 3.87 & 8,490 & 2,588 & 2003 & 184 \\
\hline Hydrothermal 2 & Production & 7.64 & 9,976 & 3,041 & 2010 & 110 \\
\hline Hydrothermal 3 & Injection & 13.54 & 10,825 & 3,299 & 2009 & 162 \\
\hline Hydrothermal 4 & Injection & 7.26 & 8,425 & 2,568 & 2009 & 91 \\
\hline Hydrothermal 5 & Injection & 5.37 & 7,622 & 2,323 & 2009 & 65 \\
\hline Hydrothermal 6 & Injection & 7.44 & 9,205 & 2,806 & 2013 & 86 \\
\hline Hydrothermal 7 & Injection & 4.91 & 8,247 & 2,514 & 2011 & 58 \\
\hline Hydrothermal 8 & Injection & 5.29 & 8,258 & 2,517 & 2012 & 64 \\
\hline Hydrothermal 9 & Injection & 2.02 & 3,080 & 939 & 2011 & 57 \\
\hline Hydrothermal 10 & Injection & 1.85 & 3,493 & 1,065 & 2011 & 28 \\
\hline Hydrothermal 11 & Injection & 2.58 & 4,294 & 1,309 & 2011 & 50 \\
\hline Hydrothermal 12 & Injection & 8.15 & 11,753 & 3,582 & 2010 & 109 \\
\hline Hydrothermal 13 & Injection & 7.67 & 12,340 & 3,761 & 2010 & 102 \\
\hline Hydrothermal 14 & Injection & 9.21 & 11,687 & 3,562 & 2010 & 128 \\
\hline WellCost Lite EGS 1 & Production & 4.54 & 8,000 & 2,438 & 2012 & 41 \\
\hline WellCost Lite EGS 2 & Production & 5.14 & 10,000 & 3,048 & 2012 & 52 \\
\hline WellCost Lite EGS 3 & Production & 6.92 & 12,000 & 3,658 & 2008 & 56 \\
\hline WellCost Lite EGS 4 & Production & 8.09 & 15,000 & 4,572 & 2008 & 59 \\
\hline WellCost Lite EGS 5 & Production & 6.27 & 8,000 & 2,438 & 2008 & 51 \\
\hline WellCost Lite EGS 6 & Production & 7.57 & 10,000 & 3,048 & 2008 & 55 \\
\hline WellCost Lite EGS 7 & Production & 8.38 & 12,000 & 3,658 & 2008 & 60 \\
\hline WellCost Lite EGS 8 & Production & 9.15 & 15,000 & 4,572 & 2008 & 66 \\
\hline WellCost Lite EGS 9 & Production & 5.01 & 8,000 & 2,438 & 2012 & 45 \\
\hline WellCost Lite EGS 10 & Production & 5.50 & 10,000 & 3,048 & 2012 & 46 \\
\hline Baker Hughes EGS 1 & Vertical & 5.70 & 7,500 & 2,286 & 2012 & 75 \\
\hline
\end{tabular}




\begin{tabular}{|l|l|r|r|r|r|r|}
\hline Baker Hughes EGS 2 & Vertical & 6.71 & 10,000 & 3,048 & 2012 & 89 \\
\hline Baker Hughes EGS 3 & $45^{\circ}$ Well & 6.54 & 9,678 & 2,950 & 2012 & 95 \\
\hline Baker Hughes EGS 4 & $45^{\circ}$ Well & 7.53 & 10,935 & 3,333 & 2012 & 102 \\
\hline Baker Hughes EGS 5 & $45^{\circ}$ Well & 8.10 & 13,420 & 4,090 & 2012 & 115 \\
\hline Baker Hughes EGS 6 & $90^{\circ}$ Well & 9.29 & 12,885 & 3,927 & 2012 & 112 \\
\hline Baker Hughes EGS 7 & $90^{\circ}$ Well & 9.17 & 12,385 & 3,775 & 2012 & 107 \\
\hline Baker Hughes EGS 8 & $90^{\circ}$ Well & 12.65 & 18,385 & 5,604 & 2012 & 145 \\
\hline
\end{tabular}

*MD is measured depth of well i.e. the length of the wellbore along its path. 
Table A-2 Probability distributions of most important well cost factors

\begin{tabular}{|c|c|c|c|c|}
\hline Factor & Unit & Per Interval & Distribution & Parameters \\
\hline Rate of Penetration (ROP) & $\mathrm{ft} . / \mathrm{hr}$ & Yes & Lognormal & $\begin{array}{l}\text { Interval 1: } \mu=14, \sigma=10 \\
\text { Interval } 2: \mu=12, \sigma=8 \\
\text { Interval 3: } \mu=11, \sigma=3 \\
\text { Interval 4: } \mu=9, \sigma=1\end{array}$ \\
\hline Rig Rental Cost & $\$ /$ day & No & Triangular & $\begin{array}{l}\text { Min }=18,000 \\
\text { Mode }=20,000 \\
\operatorname{Max}=23,000\end{array}$ \\
\hline Casing Cost & $\$ / \mathrm{ft}$. & Yes & Normal & $\begin{array}{l}\mu=\text { casing weight in } \mathrm{lb} / \mathrm{ft} . \\
\sigma=10 \% \text { of } \mu\end{array}$ \\
\hline Cement & $\$ / \mathrm{ft}$. & Yes & Triangular & $\begin{array}{l}\text { Min }=40 \\
\text { Mode }=120 \\
\text { Max }=220\end{array}$ \\
\hline Rental Equipment & $\$ /$ day & No & Uniform & $\begin{array}{l}\text { Min }=588 \\
\operatorname{Max}=9,218\end{array}$ \\
\hline Fuel & \$/gal & No & Deterministic & 4.5 \\
\hline Drill Bits & $\$ /$ bit & Yes & Normal & $\begin{array}{l}\mu=25,000 \\
\sigma=8,000\end{array}$ \\
\hline Freight \& Hauling & $\$ /$ day & Yes & Deterministic & 700 \\
\hline Air Compressors & $\$ / \mathrm{hr}$ & Yes & Uniform & $\begin{array}{l}\operatorname{Min}=50 \\
\operatorname{Max}=60\end{array}$ \\
\hline Consultants & $\$ /$ day & No & Deterministic & 400 \\
\hline Contract Labor & $\$$ & Yes & Triangular & $\begin{array}{l}\text { Min }=10,000 \\
\text { Mode }=23,000 \\
\operatorname{Max}=35,000\end{array}$ \\
\hline Mud Logging & $\mathrm{hr}$ & Yes & Triangular & $\begin{array}{l}\text { Interval 1: } 0 \\
\text { Interval } 2-4:(\mathrm{Min}=.0005 ; \\
\text { Mode }=.0008 ; \text { Max }= \\
.0012)^{*} \mathrm{MD}\end{array}$ \\
\hline Directional Drilling & $\$$ & Yes & Normal & $\begin{array}{l}0.25^{*} \text { number of drilling } \\
\text { days* }(\mu=13,000 ; \sigma=3,000)\end{array}$ \\
\hline Drilling Mud & $\$ / \mathrm{hr}$ & Yes & Lognormal & $\begin{array}{l}\mu=50 \\
\sigma=25 \\
\text { shift }=60\end{array}$ \\
\hline Rig Mobilization & $\$$ & No & Deterministic & 200,000 \\
\hline
\end{tabular}




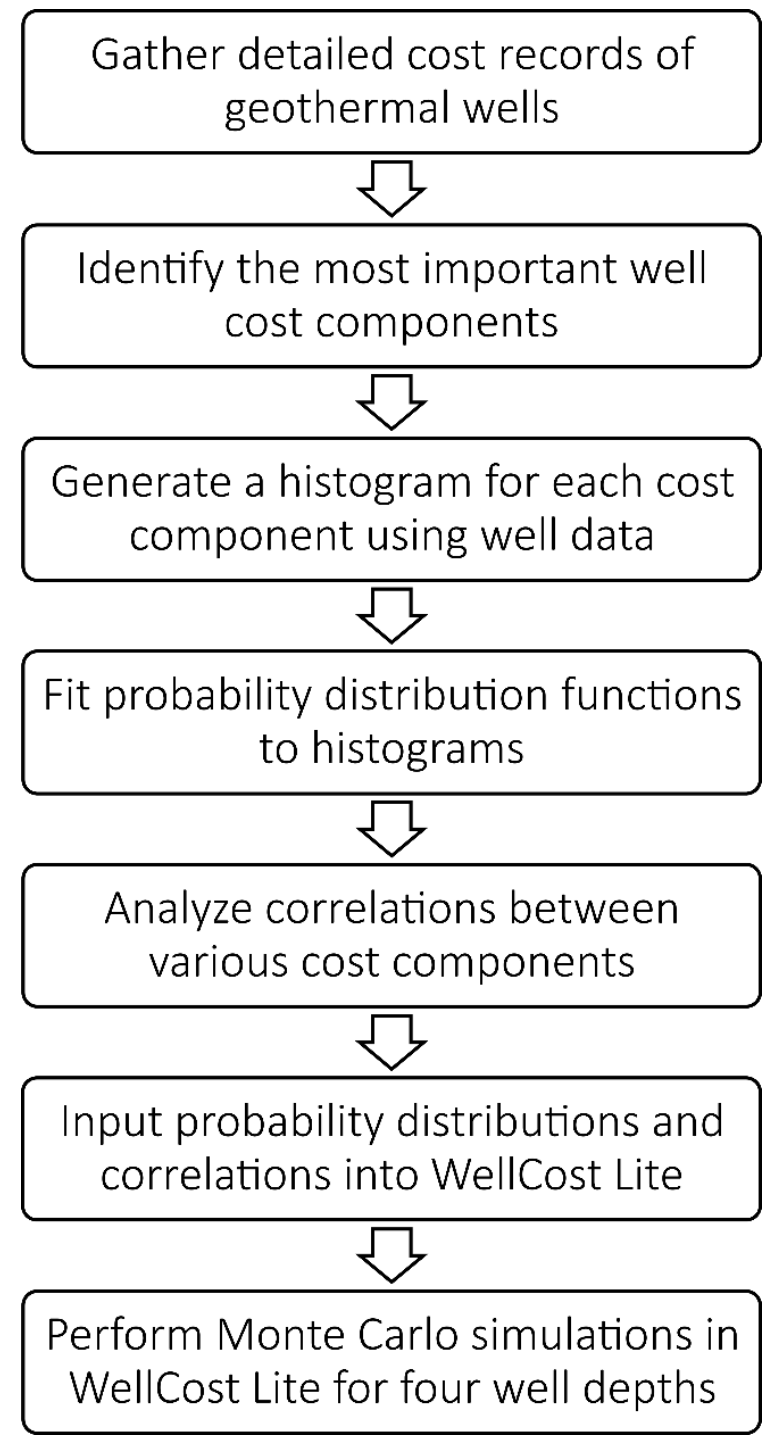




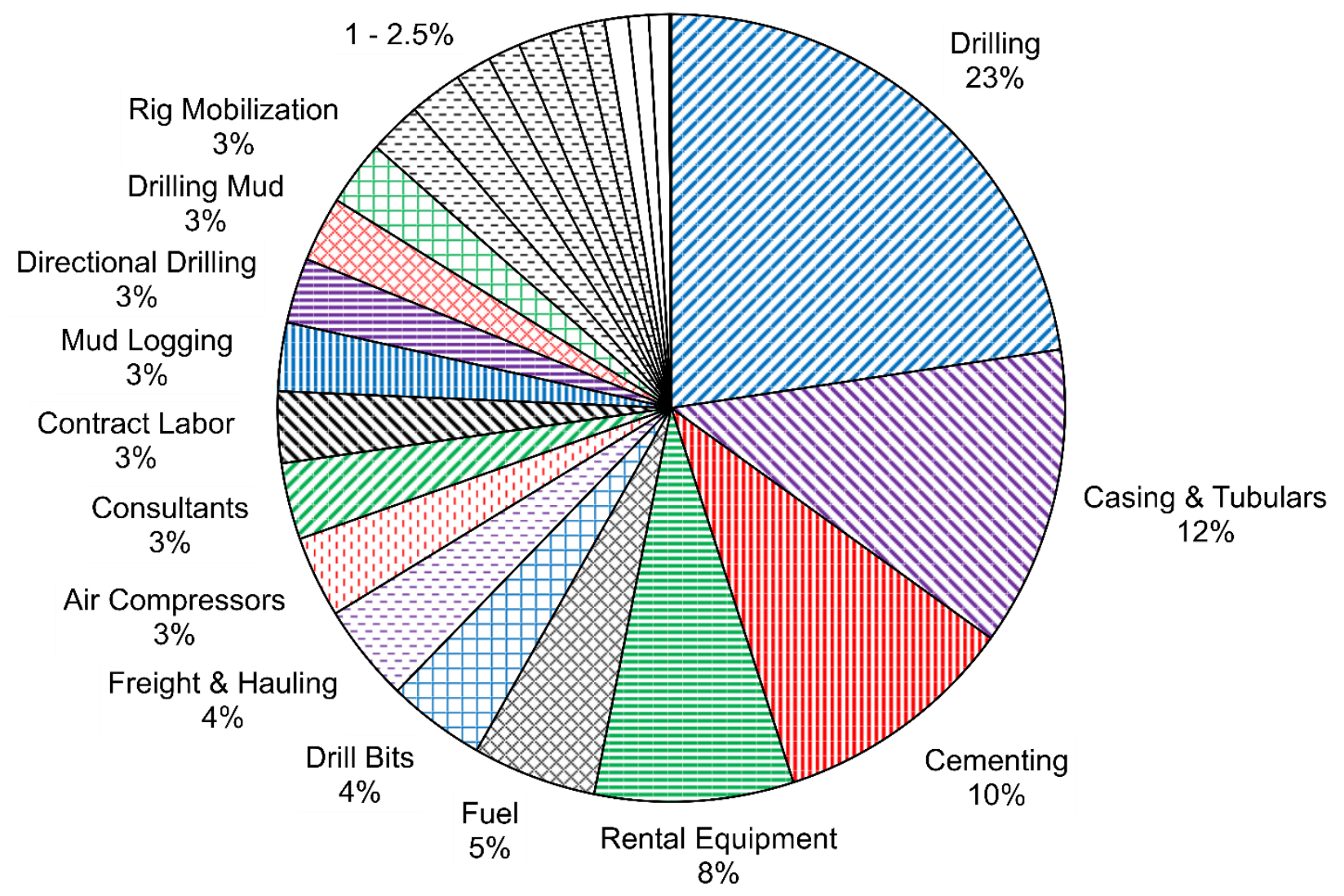

1-2.5\% : Tubular Inspection, Wellhead Equipment, Casing \& Tubular Repairs, Drilling Engineering, Contract Work, Stabilizers \& Reamers, Tools \& Supplies $0-1 \%$ : Electric Logging, Welding, Miscellaneous Fishing 


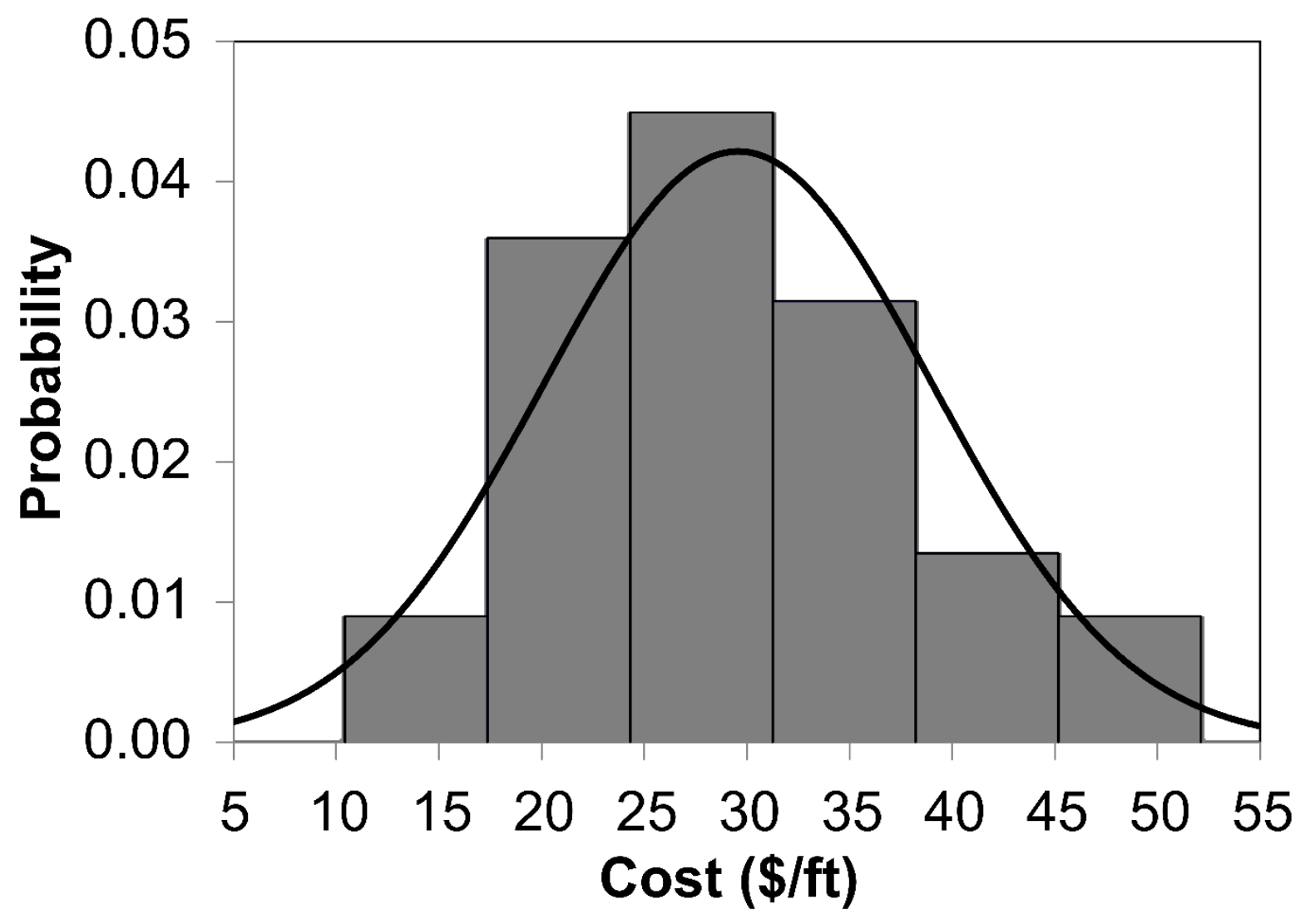


Graphical abstract

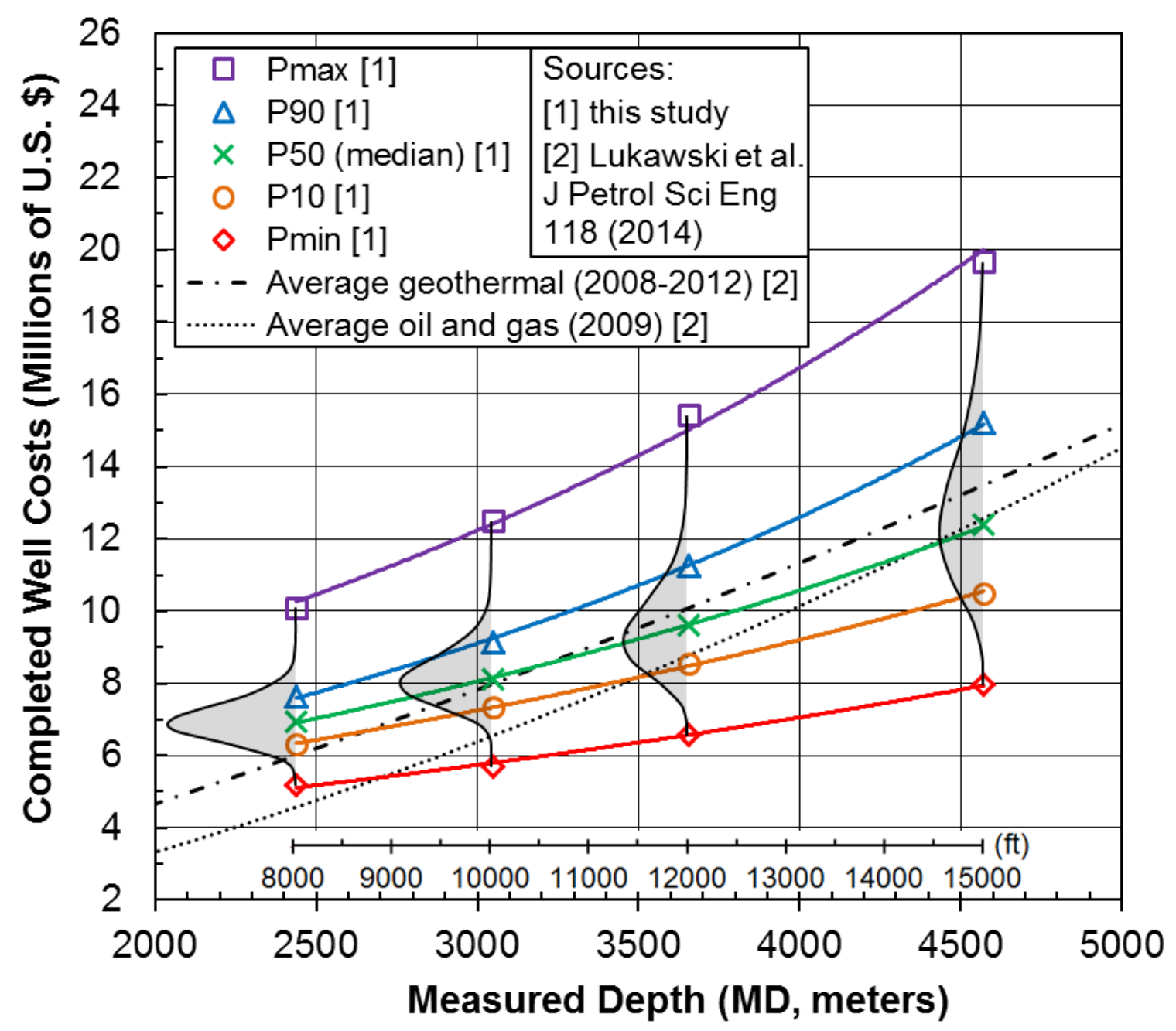

Figure: Geothermal well costs are presented as functions of well depth. Probability distributions of geothermal well costs are denoted with the grey shaded areas and a number of curves representing: the minimum cost (Pmin), $10^{\text {th }}$ percentile (P10), median cost $(\mathrm{P} 50), 90^{\text {th }}$ percentile

(P90), and the maximum well cost (Pmax). The curves from this work are compared to the average geothermal and hydrocarbon well costs from (Lukawski et al., 2014) 